\title{
MODOS DE DIZER E FAZER O CUIDADO DE ENFERMAGEM EM TERAPIA INTENSIVA CARDIOLÓGICA - REFLEXÃO PARA A PRÁTICA ${ }^{1}$ WAYS TO SAY AND TO MAKE THE NURSING CARE IN INTENSIVE CARDIOLOGIC THERAPY - REFLECTION UPON THE PRACTICE MODOS DE DECIR Y HACER EL CUIDADO DE ENFERMERÍA EN LA UNIDAD CARDIOLÓGICA DE CUIDADOS INTENSIVOS - UNA REFLEXIÓN PARA LA PRÁCTICA
}

\section{Lucia de Fátima da Silva², Marta Maria Coelho Damasceno ${ }^{3}$}

${ }^{1}$ Artigo extraído da Tese de Doutorado "Cuidado de enfermagem em terapia intensiva cardiológica: hermenêutica do cuidado fundamentada na fenomenologia heideggeriana", desenvolvida no projeto de pesquisa "Cuidado de Enfermagem: caminho para prevenir e reabilitar, financiado pelo CNPq.

${ }^{2}$ Enfermeira. Doutora em Enfermagem. Docente da Universidade Estadual do Ceará. Enfermeira do Hospital de Messejana. Líder do Grupo de Pesquisa Educação, Saúde e Sociedade (GRUPESS).

${ }^{3}$ Enfermeira. Doutora em Enfermagem. Docente do Programa de Pós-Graduação em Enfermagem da Universidade Federal do Ceará. Pesquisadora do CNPq.

\section{PALAVRAS-CHAVE:}

Cuidados de enfermagem.

Unidades de terapia intensiva. Cardiologia.

KEYWORDS: Nursing care. Intensive care units. Cardiology.

PALABRAS CLAVE:

Atención de enfermería. Unidade de terapia intensiva. Cardiologia.
RESUMO: Reflexão fundamentada nos dados coletados em uma tese de doutorado acerca do cuidado de enfermagem em terapia intensiva cardiológica. Perguntou-se às enfermeiras e auxiliares de enfermagem o que é cuidado e se observou os cuidadores executando o cuidar. Constatou-se existir diferenças entre o que é dito sobre o cuidado e o que é feito na prática, ou seja, entre a retórica e o real. Embora afirmem que o cuidado deve privilegiar procedimentos técnicos e atitudes humanísticas, a prática demonstra a relevância atribuída ao manuseio dos aparelhos e ao atendimento das necessidades biológicas. Considerou-se para esta reflexão que a prática que impõe aos profissionais o desempenho de atividades administrativo-gerenciais e as do domínio biológico não justifica as amarras aos aspectos técnicos do cuidado. $\mathrm{O}$ desafio apresentado aos sujeitos é identificar o instante em que devem enfatizar as dimensões objetivas ou aquelas da instância existencial, representativas da diversidade da sentimentalidade humana.

\begin{abstract}
This study presents reflection based on the data collected in a doctorate thesis concerning nursing care in intensive cardiologic therapy. The nurses and nurse helpers were asked what care is and if they observed the people who perform the care, executing the care procedures. It was evidenced that differences exist between what is said about the care and what is done in practice, or rather, between speech and reality. Although they affirm that the care must privilege technical procedures and humanistic attitudes, the practice demonstrates the relevance given to the use of the devices and the attendance of the biologic necessities. We considered for this reflexion that this practice gives the responsibility of performing administrative-managerial and biological activities to the professionals. Thus, it does not justify the mooring cables to the technical aspects of the care. The challenge presented to the citizens is to identify the instant where one must emphasize the objective dimensions or those of the existential area that express the diversity of human feelings.
\end{abstract}

RESUMEN: Una reflexión basada en los datos recolectados de una tesis de doctorado sobre el cuidado de enfermería en la terapia intensiva cardiológica. Se preguntó a las enfermeras y auxiliares de enfermería lo que es el cuidado y se observó a los cuidadores ejecutando el cuidar. Se constató que existen diferencias entre lo que se dice y lo que se hace en la práctica, es decir, entre la retórica y la realidad. Aunque, aseguren que el cuidado debe privilegiar procedimientos técnicos y actitudes humanísticas, la práctica muestra la importancia dada a la manipulación de los aparatos y a la atención de las necesidades biológicas. Se consideró para ello que la práctica que impone a los profesionales la ejecución de las actividades administrativo-gerenciales y las del dominio biológico no justifica estar atado a los aspectos técnicos del cuidado. El desafío presentado a los sujetos es de identificar el momento en que estar deben enfatizar las dimensiones objetivas o aquellas de la instancia existencial que expresan la diversidad de los sentimientos humanos en dicho contexto.
Endereço:

Lucia de Fátima da Silva

Av. Rogaciano Leite, 980 Apto 202

60810-000 - Cocó, Fortaleza, CE

e-mail: luciadefatima.ce@terra.com.br
Artigo original: Reflexão

Recebido em: 15 de novembro de 2004

Aprovação final: 5 de março de 2005 


\section{INTRODUÇÃO}

O ponto de partida para a presente reflexão constituiu-se dos dados coletados quando da construção da tese de doutorado sobre o cuidado de enfermagem em terapia intensiva cardiológica ${ }^{1}$. Ali, tomamos como argumento a problemática que vem envolvendo o cuidado de enfermagem naquele cenário, ou seja, a predominância dos aspectos técnico-biológicos sustentada, sobretudo, pelo fascínio que o aparato tecnológico exerce sobre os profissionais ${ }^{2}$.

À época, perguntamos aos cuidadores (enfermeiras e auxiliares de enfermagem) o que é cuidado de enfermagem, sob o princípio de que a linguagem verbal é uma forma de discurso, permitindo ao homem se expressar como sujeito que compreende, que se acha situado no mundo. Ainda, observamos esses cuidadores executando o próprio ato de cuidar, de modo a contemplar um outro aspecto da linguagem - aquele manifestado pelos gestos e até mesmo pelo silêncio ${ }^{3}$.

Efetivamente, não era objeto da tese estabelecer comparações entre o que se diz e o que se faz acerca do cuidado de enfermagem em terapia intensiva cardiológica. Era, na verdade, desvelar os significados encobertos nos modos de fazer e pensar o cuidado de enfermagem com o objetivo precípuo de compreender o fenômeno em sua pureza e, assim, aclarar a obscuridade em torno desse conceito e que, por isso mesmo, tem trazido sérias implicações na prática.

No entanto, a riqueza do material obtido revelou diferenças entre o que se diz acerca do cuidado e o que se faz na prática. Isso representou o foco de interesse da presente reflexão. Porém, para podermos proceder à discussão dos achados que sustentam a revelação mencionada, é imprescindível expô-los, conforme demonstramos a seguir.

\section{O QUE É DITO...}

Quando instadas a se pronunciar, as enfermeiras expressaram que o cuidado de enfermagem é um complexo de ações com vistas ao suprimento de necessidades circunstanciais das vastas manifestações humanas dos pacientes que, no ambiente da terapia intensiva cardiológica, ocorrem, geralmente, pelo modo científico e sistematizado de agir à beira do leito. Para dispensálo, é requerida do cuidador visão antecipada proveniente do seu saber técnico-científico e atitude humanística na relação interpessoal vivida com o paciente.

Dos auxiliares de enfermagem, conforme apreendemos, o cuidado de enfermagem é o suprimento de conforto físico e emocional, realizado mediante procedimentos técnicos desenvolvidos de vários modos, em consonância com cada situação. Tais ações são facilitadas pela proximidade, familiaridade e interação decorridas do longo tempo que estes profissionais passam junto dos pacientes. Para cuidar, segundo os auxiliares de enfermagem, é preciso ter visão antecipada, atitude e demonstração empática de atenção, préstimos, compreensão, carinho e amor, manifestadas quando se gosta da profissão e se busca satisfazer o paciente.

Mencionadas declarações abarcam uma diversidade de aspectos explicitados, a seguir, na seqüência em que foram relatados.

Para as enfermeiras, o cuidado de enfermagem foi compreendido como um complexo de ações voltadas para a satisfação das necessidades circunstanciais dos pacientes. Segundo as profissionais, o cuidado é atenção que a equipe de enfermagem dispensa ao paciente, de acordo com cada circunstância vivida por ele. Essas circunstâncias são situações passíveis de acontecer com o paciente, tanto de forma esperada quanto inesperada. Trata-se de uma atenção globalizada da equipe com objetivo de satisfazer todas as necessidades do ser humano cuidado. Conforme elas ressaltam, todas as dimensões da pessoa cuidada merecem consideração. Por isso, suas necessidades devem ser satisfeitas de maneira tal que, para cuidar, a enfermeira deve avaliar o paciente na sua dimensão física, sem, no entanto, deixar de considerar as demais manifestações, incluindo-se a psicológica e a espiritual.

Nos discursos dos auxiliares de enfermagem, ficou explicitada a compreensão de que, durante a internação em terapia intensiva, o paciente se encontra totalmente dependente da equipe de enfermagem. Cabe, portanto, ao profissional dedicar-se ao atendimento de suas necessidades. O cuidado é tudo que se faz pelo paciente, desde a higiene até o acolhimento diante de manifestações emocionais, tais como o desejo de ser ouvido em suas angústias e apreensões relacionadas à internação.

As enfermeiras ressaltaram o cuidado de enfermagem como o desempenho de ações técnicas, atribuindo relevância a essa dimensão ao considerarem o cuidado em terapia intensiva complexo, em virtude dos vários procedimentos técnicos, indispensáveis nesse ambiente, embora também percebam a complexidade do cuidar em face da diversidade de manifestações da pessoa humana. Segundo seus discursos, de cada pessoa podem ser esperadas respostas diferenciadas 
para situações similares, de modo tal que esses padrões distintos de expressão podem acontecer até com uma mesma pessoa.

A exemplo das enfermeiras, o discurso dos auxiliares de enfermagem também é ancorado na dimensão técnica do seu fazer. Eles, porém, demonstram maior destaque que aquelas profissionais no relacionado à necessidade de manifestar atenção, apoio e respeito ao paciente durante o desenvolvimento dos procedimentos técnicos.

As profissionais de nível superior discursaram em torno da compreensão do cuidado de enfermagem como antecipação para o fazer, enfatizando a necessidade de se anteciparem no preparo de condições para o atendimento das diversas situações clínicas apresentadas pelos pacientes. O planejamento da organização do ambiente, equipamentos e materiais para a realização de um procedimento de enfermagem é concebido pelas enfermeiras como um cuidado indireto por elas dispensado aos pacientes. No sentido da propagada antecipação, foi relatado também que, ao iniciar sua jornada de trabalho, além de antever possíveis situações advindas da evolução clínica dos pacientes, a enfermeira deve estar com seu espírito de cuidadora, disposta para cuidar e ajudar.

Já os auxiliares de enfermagem se referem à necessidade de se antecipar ou se preparar para o cuidado, quando consideram que estar com ambiente e equipamentos montados, testados e aptos para pronto uso é um cuidado indispensável na instância da enfermagem em terapia intensiva.

Para as enfermeiras o cuidado de enfermagem é entendido como método sistematizado e mediado pelo saber científico, ao apontarem a necessidade de tomar como base o pensamento lógico do modelo científico que vem sendo considerado como o esteio pelo qual se confere atitude científica à arte de cuidar na enfermagem. Nesse sentido, elas dizem utilizar o processo sistematizado de cuidar para colaborar no planejamento e na execução dos procedimentos, em regra, instrumentalizados tecnicamente. A utilização do saber científico é circunstancial e, de acordo com cada situação, requer da enfermeira a aplicação do seu saber.

Os auxiliares de enfermagem, por sua vez, de alguma forma também se preocuparam com o aspecto científico, ao afirmarem que se mantêm atentos quanto à observação de possíveis alterações clínicas, comunicando-se, então, com a enfermeira ou o médico de plantão a fim de serem providenciados os devidos cuidados.
Ao se posicionarem acerca do cuidado de enfermagem, as enfermeiras o destacam como demonstração de atitude humanística, considerando-o tudo que a equipe faz pelos pacientes e este tudo corresponde, por assim dizer, ao próprio cotidiano de estar-junto das pessoas de quem ela cuida. Conforme revelado, no momento em que a enfermeira começa sua jornada de trabalho, se aproxima dos pacientes e os cumprimenta, já dá início ao processo de cuidar. Assim, elas dirigiram seu discurso para a compreensão do cuidado de enfermagem globalizado e subsidiado por atitudes humanísticas na relação interpessoal com o paciente.

No contexto do discurso da humanização, as enfermeiras lembram a necessidade da participação da família no processo de cuidar, considerando que, quando propiciam a aproximação entre o paciente de terapia intensiva e seus entes queridos, estão lhes prestando cuidados. Isso porque, diante da presença da família, os doentes costumam apresentar melhora do quadro clínico e demonstram bem-estar psicológico e emocional.

Sobre o aspecto humanístico no cuidar e atentando para a família no contexto de cuidar, as enfermeiras dizem que, em algumas circunstâncias, optam por cuidar do acompanhante, mesmo antes de atender às necessidades do paciente, isso por compreenderem a importância do familiar encontrar-se fortalecido para ajudar o paciente a enfrentar aquela situação. A dimensão espiritual foi outro aspecto ressaltado pelas enfermeiras no processo de cuidar na enfermagem, apesar de não se sentirem suficientemente preparadas para a avaliação de tal nuança. Mesmo assim, ao tentarem colaborar com a satisfação das necessidades espirituais da sua clientela, disseram estar prestando cuidados de enfermagem.

Ainda, posicionando-se sobre a necessidade de incorporar atitude humanizada no processo de cuidar, afirmaram que cuidado significa as ocasiões em que os profissionais de enfermagem conseguem dar toda a assistência, ou seja, quando não se limitam à execução de intervenções técnicas, mas principalmente dispensam atenção e carinho aos doentes.

Os auxiliares de enfermagem discursaram de forma semelhante às enfermeiras. Conforme se pronunciaram, o cuidado de enfermagem é desempenhado por meio de diversos modos, traduzidos pela individualização das situações de cuidado. Para eles, cada paciente tem desejos e manifestações, tanto físicas quanto emocionais, singulares, e cada um deve ser 
tratado também de forma muito própria. Chamando a atenção para a necessidade de considerar a particularidade das situações, esses profissionais referiram que é preciso explicar, orientar e deixar claro para os pacientes os procedimentos realizados, acrescentando que têm a oportunidade de agir dessa maneira, pois passam muito tempo ao lado do paciente.

\section{O QUE É FEITO...}

Da observação realizada no cotidiano do cuidado praticado pelos profissionais de enfermagem, constatamos que embora seja ele regido por um planejamento sistematizado, o que prevalece para sua viabilização são as situações emanadas do curso clínico exibido pelos pacientes ali internados. As necessidades por eles demonstradas, em regra de ordem biológica, são o foco da atenção dos profissionais e constituem, por isso, o motivo de os fazerem permanecer próximos dos pacientes.

As enfermeiras da terapia intensiva cardiológica, depois de cada cerimônia de passagem de plantão, se ocupam do desempenho dos procedimentos denominados complexos, por se caracterizarem, essencialmente, pelo caráter invasivo. A passagem de plantão ocorre à maneira de uma procissão à beira dos leitos, na qual a equipe, coordenada por enfermeiras, descreve para o grupo que vai assumir o período de trabalho todos os detalhes com relação à identidade de cada paciente, sua evolução clínica, assim como quaisquer outras manifestações, tanto físicas quanto emocionais, além dos resultados dos cuidados prestados.

Após este ritual, os componentes da equipe de plantão passam a desempenhar a chamada rotina de trabalho. As enfermeiras iniciam a leitura de relatórios e dos registros nos prontuários dos pacientes para, em seguida, avaliarem cada um, com vistas a prescrever cuidados ou ajustar, se preciso, o plano assistencial.

A partir de então, elas contatam outros profissionais, especialmente médicos, nutricionistas e fisioterapeutas, com a finalidade de discutirem a indicação de condutas ao paciente, relacionadas a repouso, atividade física, terapêutica medicamentosa, entre outros. Daí despendem seu período de trabalho com as atividades mais complexas, geralmente, ligadas à instância instrumental, necessárias para concretizar o cuidado do paciente.

Por sua vez, os auxiliares de enfermagem, também, após cumprirem o ritual da passagem do plantão, voltam sua atenção para a realização de atividades relacionadas, essencialmente, à higiene e alimentação dos pacientes e para a administração de medicamentos.

No processo continuado do trabalho desses profissionais, percebemos que o cuidado relacionado aos aspectos físico-biológicos, relativos à preservação da vida, dispensado em uma unidade intensiva é, quase sempre, viabilizado pela utilização de instrumentos elétricos, eletrônicos e computadorizados. Esses, em virtude do seu papel de monitorizar ou manter as funções vitais, impõem tamanha relevância à observação contínua do seu funcionamento que seu manuseio pode, por assim dizer, suplantar o interesse dos profissionais pelos pacientes. Muitas vezes, é comum a atenção se voltar para os aparelhos em detrimento da pessoa que os utiliza.

Outra demanda do trabalho cotidiano, em especial das enfermeiras, é colaborar com a equipe médica na realização de procedimentos oriundos da evolução clínica dos pacientes, em geral de alta complexidade, tais como atendimento às situações de parada cardiorespiratória, implante de marcapassos artificiais provisórios, punções e dissecção de veias profundas ou de artérias, entubação endotraqueal, instalação de próteses ventilatórias, de monitorização invasiva de pressões intracardíacas e instalação de balão intra-aórtico.

Nessas situações, compete-lhes providenciar material e equipamentos destinados a viabilizar os procedimentos. Assim, mesmo a despeito de sua boa vontade, essas atividades as mantêm ocupadas com um cotidiano instrumental que nem sempre favorece a aproximação com a pessoa cuidada.

Quanto aos auxiliares de enfermagem, além de participarem dessas situações circunstanciais, cumprem seu trabalho, essencialmente, com as práticas descritas (higiene, alimentação e administração de medicamentos), as quais por se constituírem demanda continuada, lhes consomem grande parte do turno de trabalho, e implicam maior contato com os pacientes internados.

Desse modo, os profissionais de enfermagem são chamados continuamente a se envolverem com uma prática de cuidados regidos por instrumentos e materiais relacionados à instância técnica e biológica, ficando seu cotidiano aprisionado a esses aspectos.

Com efeito, observando o dia-a-dia da prática de cuidar, percebemos que os profissionais de enfermagem estão priorizando continuamente a antevisão das possíveis intercorrências no curso clínico dos pacientes que lhes demande cuidado. Eles, por exemplo, freqüentemente se ocupam, diante da gravidade dos pacientes, de aproximar carrinhos contendo material e 
equipamentos de atendimento à parada cardíaca.

Tivemos a oportunidade de observar situações nas quais tanto enfermeiras quanto auxiliares de enfermagem, em face de alterações clínicas ou hemodinâmicas de um paciente, ou ainda na iminência de uma ocorrência dessa ordem, antecipavam-se na adequação do ambiente para o atendimento a uma parada cardiorespiratória. Logo, por exemplo, o carrinho de urgência era posto o mais próximo possível do paciente a fim de não serem surpreendidos com situações inesperadas. É, pois, raro a aproximação ao doente ocorrer espontaneamente, como, por exemplo, para conversar ou para afagá-lo.

O comum é os profissionais de enfermagem se aproximarem dos pacientes quando vão realizar algum procedimento técnico. $\mathrm{Na}$ situação particular da terapia intensiva cardiológica, as enfermeiras evidenciam solidariedade e interesse por todos os problemas apresentados pelos pacientes. No entanto, elas acabam por priorizar aqueles da instância instrumental e, no mais das vezes, é por esse meio que elas identificam as manifestações existenciais de sua clientela.

Nem sempre, porém, essas atitudes, ditas por elas como relevantes, ocorrem na prática. É, em geral, quando da realização de um banho, de um curativo, de uma medicação ou mesmo da viabilização de uma das etapas do processo sistematizado, que os profissionais de enfermagem se aproximam dos pacientes e, nessas ocasiões, lhes transmitem apoio, segurança e conforto, manifestações também extensivas aos seus familiares e acompanhantes.

Mas esses vínculos não se aprofundam a ponto de facilitar as relações terapêuticas entre profissionais e pacientes, pois apenas os auxiliares de enfermagem, em virtude da necessidade de realizarem as atividades de características continuadas junto dos pacientes, se fazem perceber como próximos e íntimos deles.

Em uma situação de higienização no leito, duas auxiliares de enfermagem se aproximaram cordialmente da paciente, a cumprimentaram com expressões de bom-dia, explicaram a necessidade do banho, bem como dos passos a serem adotados. A seguir, após darem início ao banho, passaram a conversar entre si, esquecendo a atenção que, inicialmente, demonstravam para com a doente.

Esse tipo de postura foi constatado em outras situações observadas no processo de cuidar. A paciente, por sua vez, mantinha-se passiva, embora tenhamos percebido certo constrangimento na sua expressão facial e um cuidado muito especial em se proteger com os lençóis para seu corpo não ficar exposto. Não são raros os momentos em que a equipe de enfermagem e até outros profissionais, ao realizarem procedimentos à beira do leito, mantêm-se alheios e indiferentes ao atendimento das necessidades não configuradas como de domínio biológico.

\section{A REFLEXÃO...}

Segundo mostra a literatura, o cuidado de enfermagem como foco de atenção dos enfermeiros não é recente. Assim, é que se lançaram à propagação da importância de estudá-lo com o intuito de verificar sua manifestação na profissão, compreendendo-o como consubstanciado por dimensões não somente biológicas, mas também existenciais, éticas, culturais, políticas e intelectuais ${ }^{4-9}$.

No entanto, no relacionado ao cuidado em terapia intensiva cardiológica, constatamos um distanciamento entre o que é dito e o que é realizado na prática profissional, ou seja, entre a retórica e o real.

A retórica é a "arte de persuadir pelo uso de

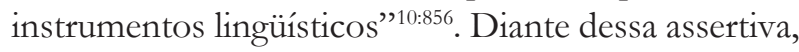
pode-se dizer que o discurso na retórica é pensado antes mesmo de ser pronunciado, ainda que isso ocorra mediante formulações do falatório, que levam o homem a viver a ambigüidade de pensar que algo acontece quando na verdade aquilo não ocorreu. Isso porque a ambigüidade "oferece à curiosidade o que ela busca e confere ao falatório a aparência de que nele tudo se decide" ${ }^{3: 235}$.

O real, por sua vez, é tudo que existe de fato, correspondendo aos vários sentidos do termo realidade que, propriamente, significa "o modo de ser das coisas existentes fora da mente humana ou independente dela"10:831.

Assim, quando os enfermeiros discursaram sobre o cuidado de enfermagem o fizeram de modo a privilegiar os aspectos técnico-biológicos, muito embora tenham demonstrado a importância de valorização da dimensão existencial, contemplando o ser humano como um todo. Mas, ao serem observados em sua prática, sua intenção não se manifesta em gestos, pois o que vimos foi o cotidiano profissional aprisionado ao fazer instrumental, nem sempre revelando interesse por atender às várias dimensões das necessidades humanas.

Provavelmente, isso se deva ao estabelecimento de protocolos de cuidar elaborados pela própria instituição de trabalho ${ }^{11}$, os quais estimulam, com apoio 
na legislação que rege o exercício profissional ${ }^{12}$, a divisão técnica do cuidado ${ }^{13}$, ao determinarem que o desempenho de atividades de alta complexidade técnicocientífica seja exclusivo das enfermeiras.

No ambiente de terapia intensiva cardiológica, as enfermeiras vivem o cotidiano de cuidar de pessoas que requerem administração de drogas endovenosas sofisticadas ligadas a monitores invasivos e não invasivos dos sinais vitais, a próteses ventilatórias mecânicas, a marcapassos cardíacos artificiais e a outros artefatos, tais como o balão intra-aórtico. Esses dispositivos, por serem responsáveis pela propulsão da musculatura cardíaca ou pela manutenção de um padrão respiratório compatível com a vida, exigem a observação contínua de seu funcionamento, pois são asseguradores da vida do paciente ${ }^{14}$.

É possível que a constante necessidade de os pacientes internados em unidades de terapia intensiva serem submetidos a procedimentos clínico-cirúrgicos, quer sejam diagnósticos, quer sejam terapêuticos, contribua para as enfermeiras se envolverem com o manuseio de materiais e equipamentos de um modo tal que, em algumas situações, esses passam a merecer mais atenção que os próprios doentes internados.

É comum, ainda, as enfermeiras serem chamadas a assumir atividades administrativo-gerenciais e, por isso, precisarem se dividir entre essas atribuições e a permanência junto dos doentes.

No entanto, as determinações protocolares e as atividades administrativo-gerenciais, tampouco o estado crítico dos pacientes não podem justificar as amarras aos aspectos técnico-biológicos do cuidado. Elas poderiam e deveriam otimizar o tempo dispensado para levantar dados sobre o paciente, prescrever intervenções, implementá-las e avaliá-las para tentar abarcar as outras faces do cuidado de enfermagem. Afinal, "talvez o tempo do cuidado dependa do valor que damos a ele. Se soubéssemos valorizar os pacientes enquanto e quando estivermos com eles [...] possamos otimizar o tempo..."15:17.

Ademais, os auxiliares de enfermagem, embora tenham discursado de modo semelhante às enfermeiras acerca da valorização da instância técnica do cuidar, demonstraram esforços no sentido de se aproximarem dos pacientes, a ponto de lhes proporcionar mais atenção. Mesmo assim, foram presenciadas situações nas quais nem sempre o paciente é o centro do cuidado desses profissionais.

A eles são determinadas, pelos protocolos de atividades, tarefas como higiene, alimentação, preparo e administração de medicamentos, ações que proporcionam um tempo maior despendido junto do leito dos pacientes. Essa permanência maior, portanto, poderia ser um momento propicio para fortalecer a proximidade entre auxiliares de enfermagem e doentes.

Questionamos, porém, por que esse tempo não é melhor aproveitado para o atendimento das necessidades psico-sócio-espirituais, uma vez que a ação de cuidar de pessoas requer da enfermagem mais do que competência técnica, pois é indiscutível ser necessário conhecer a pessoa de quem cuida, bem assim que saiba como essa pessoa encara sua enfermidade, ensejando a ela a oportunidade de expressar seus sentimentos ${ }^{16}$.

A dissonância entre a teoria (retórica) e a prática (real) na enfermagem não é uma discussão nova, no entanto ela continua merecendo consideração. A aparência e o real nem sempre se correspondem; isso pode relacionar-se ao fato de que o processo de trabalho em saúde costuma ser unidirecional - sujeito/objeto, enquanto a comunicação plena exige multidirecionalidade entre dois sujeitos que se encontram no mundo ${ }^{17}$.

Pretendemos com essa reflexão alcançar os centros formadores de maneira tal que a formação dos futuros profissionais seja por ela alimentada. Se a construção desse comportamento tiver base na formação profissional, certamente o intuito da prática de cuidar na enfermagem subsidiada pela compreensão existencial da pessoa cuidada será atingido. Estaríamos, por essa via, nos distanciando da mera retórica do cuidado humanizado e nos dirigindo para o cuidado autêntico do outro.

Convém ainda ressaltar a importância atribuída ao acordo entre formação e competência profissionais, pois o processo de formação inicial e continuada de uma pessoa é indispensável para ela adquirir competências voltadas a capacitá-la para demonstrar o melhor serviço que possa oferecer ${ }^{18}$. Nesse sentido, lembramos, alunos e professores precisam se familiarizar com as diversas dimensões ou ordem das coisas e não apenas com alguns de seus elementos ${ }^{19}$.

Diante da compreensão de que os profissionais nem sempre atendem a essas expectativas dos pacientes, há de se refletir sobre qual a real importância da dimensão técnica sobre o cuidado de enfermagem, pois se o cuidado instrumental é tão relevante para enfermeiras e auxiliares de enfermagem, seria essa prática o essencial para a enfermagem? Se não fosse a atividade instrumental do cuidar, em que se constituiria a profissão? Existe propriamente o cuidado na enfermagem? 
Ela só tem razão de ser pelo fazer técnico-científico? Onde se perdeu a dimensão humanística no processo de cuidar na enfermagem?

Portanto, merece considerar que mesmo sendo o tecnicismo uma realidade necessária em nossos dias, o cuidado de enfermagem, até quando mediado por procedimentos advindos desta tecnologia, deve ser guiado pela subjetividade característica do encontro interpessoal que ocorre no processo de cuidar ${ }^{20}$.

Mesmo ante a importância do uso de instrumentos para cuidar em terapia intensiva, é preciso se manter a atenção para a valorização das expressões humanas de pacientes e seus familiares. Assim, o desafio proposto às enfermeiras e auxiliares de enfermagem é identificar o instante em que devem dar maior importância e ênfase às dimensões objetivas e mensuráveis ou àquelas da instância existencial, representativas da diversidade da sentimentalidade humana ${ }^{21}$.

Afinal, fazer enfermagem significa demonstrar disposição para cuidar de outras pessoas por meio da valorização das sentimentalidades humanas, sendo imprescindível a sinalização de atitude ética, não compreendida meramente como concordância moral, mas sim como compromisso de respeito ao paciente envolvido na relação interpessoal do cuidado; assim como de atitude estética, percebida como o sentimento de valorização dessa relação com vistas a harmonizar o pensar e o fazer no cuidado de enfermagem.

Ao entender a enfermagem como uma ciência possuidora de bases tanto biológicas quanto humanas, pode-se afirmar que ela também se manifesta por experiências de cuidado, expressão desse fazer e compreensão de sua prática. Dessa maneira, pode ser pensado que o discurso retórico de seus profissionais não apresenta consonância com a realidade pelo fato de se manterem eles essencialmente presos à instância da experiência do seu fazer, ou seja, no cotidiano de desempenhar procedimentos técnicos, não atentando para a expressão de sentimentos na sua relação com as pessoas cuidadas e, por isso, vivendo a dificuldade de compreender o cuidado como essência de sua atividade profissional.

Existe descompasso entre a retórica e o real, revelando profunda ambigüidade no cuidado de enfermagem. A noção de cuidado de enfermagem é ao mesmo tempo uma aproximação e um desvio do conceito originário de cuidado humano, revelando-se em uma ambigüidade ou até mesmo em uma contraditoriedade.

\section{REFERÊNCIAS}

1 Silva LF. Cuidado de enfermagem em terapia intensiva cardiológica: hermenêutica do conceito fundamentada na fenomenologia heideggeriana [tese]. Fortaleza (CE): Programa de Pós-Graduação em Enfermagem/UFC; 2002.

2 Nunes WA. Do cuidar com tecnologia à tecnologia do cuidar [tese]. Ribeirão Preto (SP): Programa de Pós-Graduação em Enfermagem/EER-USP; 1999.

3 Heidegger M. Ser e tempo. 4a ed. Petrópolis: Vozes; 1993.

4 Waldow VR. Cuidado humano: o resgate necessário. Porto Alegre: Sagra Luzzato; 1998.

5 Silva AL. O estado da arte do cuidado de enfermagem. Texto Contexto Enferm. 1997 Maio-Ago; 6(2):19-32.

6 Chinn PL, Kramer MK. Theory and nursing: a systematic approach. 4th ed. St. Louis: Mosby; 1995.

7 Watson J. Nursing - human science and human care: a theory of nursing. New York: National League for Nursing; 1999.

8 Collière MF. Promover a vida: da prática das mulheres de virtude aos cuidados de enfermagem. Lisboa: Sindicato dos Enfermeiros Portugueses; 1999.

9 Leopardi MT. Cuidado face ao trabalho da enfermagem. Florianópolis: 1999. Mimeografado.

10Abbagnano N. Dicionário de filosofia. 3a ed. São Paulo: Martins Fontes; 1999.

11Hospital de Messejana (CE). Manual de regimento interno e normas funcionais da Unidade de Enfermagem. Fortaleza: Chefia da Unidade de Enfermagem; 1999.

12Conselho Regional de Enfermagem (CE). Legislação. Fortaleza: COREN-CE; 2002.

13Almeida MCP, Rocha JSY. O saber de enfermagem e sua dimensão prática. São Paulo: Cortez; 1986.

14Goldman L, Braunwald E. Cardiologia na clínica geral. Rio de Janeiro: Guanabara Koogan; 2000.

15Silva MJP. Qual o tempo do cuidado? Clarificando a intenção. In: Silva MJP, organizadora. Qual o tempo do cuidado? Humanizando os cuidados de enfermagem. São Camilo: Edições Loyola; 2004. p. 13-17.

16Kretlow F. A phenomenological view of illness. J Adv Nurs. 1990 Dec; 7(2):8-10.

17Faria EM. O diálogo das intersubjetividades na saúde. In: Leopardi MT, organizador. Processo de trabalho em saúde: organização e subjetividade. Florianópolis: Programa de Pós-Graduação em Enfermagem/UFSC: Papa Livros; 1999. p. 121-50.

18Vergnaud G. Quelle théorie pour comprendre les relations entre savoir-faire et savoir? In: Bentolila A. Les entretiens nahan: savoir et savoir-faire. Paris: Nathan ; 1995. p. 5-20. 
19Reibnitz KS, Prado ML. Formação do profissional críticocriativo: a investigação como atitude de (re)conhecimento do mundo. Texto Contexto Enferm. 2003 Jan-Mar; $12(1): 26-33$.

20Santoro DC. O cuidado de enfermagem na unidade coronariana: um ensaio sobre a dimensão da subjetividade do cuidar [tese]. Rio de Janeiro (RJ): Programa de PósGraduação em Enfermagem/UFSC; 2000.
21Barbosa SFF. A transcendência do emaranhado tecnológico em cuidados intensivos: a (re)invenção possível. Blumenau: Nova Letra; 1999. 